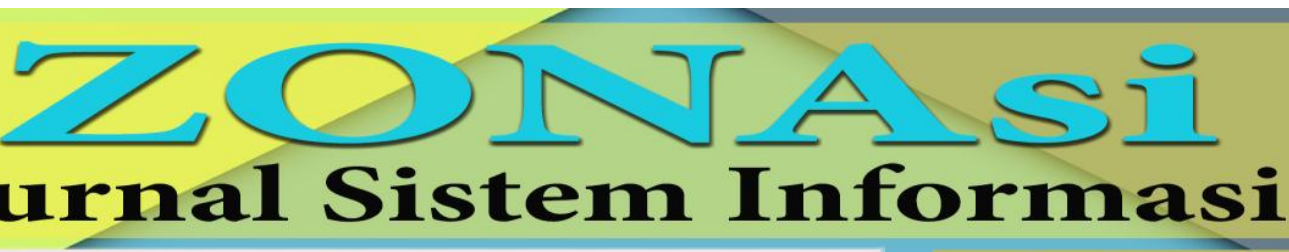

\title{
PENGELOMPOKAN PENERIMAAN ASISTEN LABORATORIUM TEKNIK INFORMATIKA DENGAN MENGGUNAKAN K-MEANS DI UNIVERSITAS PERADABAN
}

\author{
Nurul Mega Saraswati ${ }^{1}$, Rito Cipta Sigitta $\mathbf{H}^{2}$.
}

1,2 Universitas Peradaban

Departemen Teknik Informatika Fakultas Sains dan Teknologi Universitas Peradaban

Jln. Pagojengan KM.03, Paguyangan, Glempang, Pagojengan, Kec. Paguyangan,

Kabupaten Brebes, Jawa Tengah. Kode Pos. 52276, (0289) 432032

e-mail: ${ }^{1}$ nurul.mega.s@gmail.com, ${ }^{2}$ ritocipta@peradaban.ac.id

\begin{abstract}
ABSTRAK
Di Jurusan Teknik Informatika, Universitas Peradaban tidak hanya teori, tetapi terdapat pratikum. Keberhasilan pada proses belajar mengajar di Jurusan Teknik Informatika, Universitas Peradaban tidak hanya dari dosen saja, tetapi dari beberapa asisten pratikum laboratorium. Asisten disini membantu dosen dalam melayani dan memberikan arahan matakuliah yang sedang berlangsung, maka itu diperlukan calon asisten pratikum yang memiliki kompetensi dan ketangkasan dalam kesusaian silabus yang diterapkan. Data mining bisa digunakan dalam pengelompokan data satu/lebih. Di penelitian yang dilakukan menerapkan data mining menggunkan metode K-Means. Atribut yang digunakan adalah IPK, nilai matakuliah pemograman, nilai matakuliah multimedia, dan nilai matakuliah jaringan. Sampel yang digunkan adalah 20 calon asisten laboratorium. Hasil pengujian yang dilakukang dengan Rapid Miner nilai $k 3$ adalah Cluster 1 berjumlah 6 anggota, Cluster 2 berjumlah 5 anggota, dan Cluster 3 berjumlah 9 Anggota.
\end{abstract}

Kata kunci: pemilihan asisten laboratorium, k-means, klasifikasi

\section{Abstrak}

In the Department of Informatics, University of Civilization is not only theory, but there is a practice. The achievement of the teaching and mastering process within the Department of Informatics, the University of Civilization not best from lecturers however assistants from numerous laboratory practicum. Assistants here assist lecturers in serving and giving on-going course direction, so it is necessary for prospective assistant practitioners who have competence and agility in the suitability of the syllabus applied. Data mining can be used in grouping one / more data. In research conducted applying data mining using the K-Means method. The attributes used are the GPA, the value of the programming course, the value of the multimedia course and the cost of the community course, The sample used was 20 prospective laboratory assistants. The test results conducted by Rapid Miner $3 k$ value is numbered 6 members cluster 1, cluster 2 numbered 5 members, and cluster 3 totaled 9 members.

Keywords: a selection of laboratory assistants, $k$-means, classification 


\section{PENDAHULUAN}

Perkembangan teknologi informasi semakin luas dan sangat pesat, salah satunya di bidang Pendidikan dalam mengolah data[1]. Teknologi informasi di pendidikan dirasakan bisa menjadi trobosan untuk analisis masalah serta memecahkan masalah dan medapatkan sebuah solusi. Instansi pendidikan di era 4.0 sekarang ini banyak memanfaatkan teknologi informasi untuk mengolah data serta proses belajar mengajar. Universitas Peradaban bumiayu brebes merupakan salah satu dari beberapa instansi perguruan tinggi yang berada di kota Brebes dan di dalamnya ada lima Fakultas serta 13 acara Studi. Didalam proses belajar mengajar pada Universitas Peradaban tidak hanya menerapkan metode secara teori, tetapi juga praktikum khususnya Fakultas Ilmu Sains dan Teknologi dimana pada sistem pembelajaran tidak hanya teori saja yang diterapkan namun juga pembelajaran berbasis praktikum dilaksanakan[2].

Laboratorium adalah tempat yang dilengkapi dengan peralatan praktikum. dalam praktikum laboratorium di mana siswa dapat berinteraksi menggunakan berbagai media yang telah disediakan sehingga dapat menghasilkan pengalaman belajar. praktikum adalah bagian dari pembelajaran yang bertujuan untuk membuat siswa menerima kesempatan untuk menguji dan menerapkan dalam situasi nyata yang diperoleh di teori. Praktikum dalam sebuah proses belajar mengajar bisa didefinisikan sebagai metode mendidik untuk belajar dan mempraktekkan semua kegiatan dalam proses belajar untuk menguasai keterampilan. Hal ini memberikan bagaimana peran kegiatan praktis sangat penting untuk mencapai tujuan pendidikan.

Pada program studi Teknik Informatika, proses belajar mengajar penyampaian materinya tidak hanya menggunakan teori saja, tetapi beberapa matakuliah terdapat penerapan teori melalui pratikum di laboratorium komputer. Disaat pertemuan pratikum berlangsung terkadang dosen tidak sanggup untuk menangani dan melayani setiap pertanyaan dari mahasiswa yang mengalami kesulitan. Disini dosen membutuhkan seorang asisten laboratorium di setiap laboratorium Komputer[3]. Salah satu untuk kelancaran pratikum dan bertanggung jawab kelangsungan proses mengajar adalah seorang asisten laboratoriun untuk membantu dosen. Tugas asisten adalah sebagai Instruktur mahasiswa sesuai dengan memandu materi praktik agar susaian silabus yang diterapkan. Seorang asisten laboratorium adalah instruktur praktikum di laboratorium komputer, sehingga penerima Asisten Laboratorium dituntut agar lebih selektif yang akan bekerja pada laboratorium komputer.

Koordinator mebawahi Assistant laboratorium, harus mengetahui kemampuan masingmasing asisten laboratorium untuk menentukan kualitas pengajaran yang diberikan kepada siswa. Maka perlu sebuah metode untuk menentukan kemampuan seorang asisten pada mengajar salah satunya adalah untuk mengevaluasi kemampuan seorang asisten di laboratorium. Untuk mengolah data dari evaluasi tersebut menggunakan sebuah metode, salah satu metode yang dapat digunakan adalah data mining untuk mencari pola atau informasi menarik pada data yang dipilih. Teknik, metode, atau prosedur dalam solusi data mining sangat bervariasi. Pemilihan metode atau prosedur solusi yang tepat tergantung pada tujuan dan proses KDD secara holistik [4]. salah satu metode yang ada dalam data mining yang digunakan dalam Penelitian adalah pengelompokan (Clustering) di mana metode tersebut mengidentifikasi objek yang memiliki karakteristik tertentu yang sama dan kemudian mengenakan karakteristik menjadi "vektor karakteristik" atau "centroid.

Beberapa penulis sebelumnya sudah menerapkan teknik Clustering K-means ke dalam penelitian dalam hal pengelompokan data, antara lain:

Pada penelitiannya "metode klasifikasi dicirikan oleh K-means analisis cluster". Penulis studi menjelaskan bahwa metode K-means analisis cluster relatif efektif diterapkan dalam proses mengklasifikasikan Karakteristik dari objek penelitian. Algoritma K-means juga tidak dipengaruhi oleh urutan objek yang digunakan, ini terbukti ketika penulis mencoba untuk memilih titik awal pusat cluster salah satu objek di awal perhitungan [5]

Penelitiannya berjudul "implementasi dari $K$-means Clustering algoritma untuk menentukan strategi pemasaran President University". Tujuan dari penulisan yang dijelaskan dalam makalah ini penulis menunjukkan bahwa dari pengolahan data untuk membantu 
mahasiswa Marketing Presiden unversity dalam pemasaran serta mencari mahasiswa baru dari berbagai kota di Indonesia, hasilnya relatif efisien dan efektif [6].

Untuk mengidentifikasi cakupan awan di atas daerah Thailand dengan memakai data satelit dan prosedur pemecahan $K$-means clustering. tetapi, hasilnya dijelaskan pada penelitian menyampaikan beberapa isu awal tentang kemungkinan analisis cuaca berasal dari asumsi awan dan akan bermanfaat buat studi lanjut saat data lainnya tersedia[7].

Dari yang dijabarkan diatas, maka penulis membuat clustering tentang pengelompokan penerimaan asisten laboratorium di teknik Informatika Universitas Peradaban dengan menggunakan metode $K$-Means. Sebab $K$-means memiliki kemampuan mengelompokkan data pada jumlah yang relatif besar menggunakan waktu komputasi yang cepat serta efisien. $K$ Means adalah salah satu algoritma clustering menggunakan metode partisi (partitioning method) yang berbasis titik pusat (centroid). Metode ini disebut tepat sebab untuk mengelompokkan data sesuai titik pusat cluster terdekat dengan data..

\section{TINJAUAN PUSTAKA}

\subsection{Data Mining}

Data Mining atau Knowledge Discovery in Database (KDD) adalah suatu proses aktivitas yang terdiri dari pengumpulan, pemakaian dan historis pada kesamaan keadaan dan memiliki pola hubungan dalam dataset berukuran besar[8]. Ada 2 jenis metode data mining yaitu, Predictive metode dan descriptive metode. Predictive metode berupa proses dalam menetukan pola data untuk memprediksikan beberapa variabel yang tidak mengenali nilainya, contohnya seperti classification, regresi, dan deviasi. Descriptive motode berupa proses dalam mengalami persamaan dari data disuatu basis data, contohnya clustering, association, dan sequential mining Tahapan di KDD [9] pada data mining, yaitu :

- Pemberisihan Data digunakan untuk mengilangkan noise data yang tidak konsisten.

- Integrasi data digunakan dalam penggabungan data.

- Seleksi Data digunakan dalam pengambilan data yang saling terkaitan untuk dianalisis.

- Tranformasi Data adalah proses untuk mengubah data menjadi yang sesuai pada data mining.

- Data mining adalah proses dalam menerapkan suatu metode untuk menghasilkan pola data.

- Evaluasi pola digunakan dalam menentukan pola yang menarik yang mewakili knowledge dari pengukuran pola.

- Presentasi Pengetahuan adalah dimana teknik visualisasi dan representasi knowledge untuk menampilkan knowledge pada pengguna.

\subsection{Clustering}

Salah satu metode yang diterapkan dalam KDD adalah clustering [10]. Clustering adalah membagi data ke dalam grup-grup yang mempunyai obyek yang karakteristiknya sama. [11]clustering adalah mengelompokkan item data ke dalam sejumlah kecil grup sedemikian sehingga masing-masing grup mempunyai sesuatu persamaan yang esensial.

Clustering memegang peranan penting dalam aplikasi data mining, misalnya eksplorasi data ilmu pengetahuan, pengaksesan informasi dan text mining, aplikasi basis data spasial, dan analisis web. Clustering diterapkan dalam mesin pencari di Internet. Web mesin pencari akan mencari ratusan dokumen yang cocok dengan kata kunci yang dimasukkan. Dokumendokumen tersebut dikelompokkan dalam cluster-cluster sesuai dengan kata-kata yang digunakan[12].

\subsection{Algoritma K-Means}

Algoritma K-Means merupakan algoritma klasterisasi yang mengelompokkan data berdasarkan titik pusat klaster (centroid) terdekat dengan data. Tujuan dari K-Means adalah pengelompokkan data dengan memaksimalkan kemiripan data dalam satu klaster dan meminimalkan kemiripan data antar klaster. Ukuran kemiripan yang digunakan dalam klaster 
adalah fungsi jarak. Sehingga pemaksimalan kemiripan data didapatkan berdasarkan jarak terpendek antara data terhadap titik centroid.

Tahapan awal yang dilakukan pada proses klasterisasi data dengan menggunakan algoritma K-Means adalah pembentukan titik awal centroid cj Pada umumnya pembentukan titik awal centroid dibangkitkan secara acak. Jumlah centroid cj yang dibangkitkan sesuai dengan jumlah klaster yang ditentukan di awal. Setelah $\mathrm{k}$ centroid terbentuk kemudian dihitung jarak tiap data xi dengan centroid ke-j sampai k, dinotasikan dengan d (xi,cj). Terdapat beberapa ukuran jarak yang digunakan sebagai ukuran kemiripan suatu instance data, salah satunya adalah jarak Euclid. Perhitungan jarak Euclidean seperti pada Persamaan 1.

$$
d(X i, C j)=\sqrt{\sum_{i=1}^{N}(X i-C j)^{2}}
$$

Jika $d(X i, C j)$ semakin kecil, kesamaan antara dua unit pengamatan semakin dekat. Syarat menggunakan jarak Euclid adalah jika semua fitur dalam dataset tidak saling berkorelasi. Jika terdapat fitur yang berkorelasi maka menggunakan konsep jarak Mahalanobis[13].

kelanjutan dari jarak tersebut dicari yang terdekat sehingga data akan mengelompok berdasarkan centroid yang paling dekat[14]. Tahap berikutnya adalah update titik centroid dengan menghitung rata-rata jarak seluruh data terhadap centroid. Selanjutnya akan kembali lagi ke proses awal. Iterasi ini akan diulangi terus sampai didapatkan centroid yang konstan artinya titik centroid sudah tidak berubah lagi. Atau iterasi dihentikan berdasarkan jumlah iterasi maksimal yang ditentukan.

\section{KERANGKA PEMIKIRAN}

Tahapan penelitian yang akan dilakukan meliputi identifikasi masalah dan pengumpulan data, approach, development, Implementasi dan hasil. Tahapan tersebut bisa dilihat pada gambar dibawah ini:

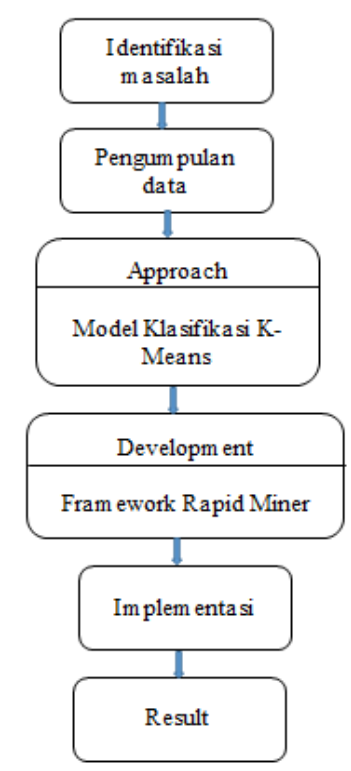

Gambar 1. Kerangka Pemikiran

\subsection{Identifikasi Masalah}

Penentuan asisten laboratorium berdasarkan kinerja dan pemahaman materi serta berkompeten dalam bidang Teknik Informatika. Selama ini pengangkatan asisten laboratorium di Prodi teknik Informatika Universitas peradaban tidak menggunakan kriteria-kriteria 
tertentu. Pada penelitian ini akan dilakukan untuk klasifikasi mahasiswa Universitas Peradaban jurusan Teknik Informatika berdasarkan IPK, nilai matakuliah pemograman, nilai matakuliah multimedia, dan nilai matakuliah jaringan dari mahasiswa yang mendaftar sebagai calon asisten laboratorium agar diperoleh asisten laboratorium yang sesuai dengan kompetensi. Setelah mendapatkan data yang akan di Classification, langkah selanjutnya adalah melakukan proses klasifikasi data dengan algoritma K-Means dengan 3 kelas.

\subsection{Dataset}

Contoh data yang digunakan dalam penelitian untuk menentukan tenaga asisten laboratorium bisa dilihat pada tabel dibawah.

Tabel 1. Calon Asisten Laboratorium

\begin{tabular}{|c|c|c|c|c|c|}
\hline No & Nama & IPK & $\begin{array}{l}\text { Nilai Matkul } \\
\text { Pemograman }\end{array}$ & $\begin{array}{c}\text { Nilai } \\
\text { Matkul } \\
\text { Multimedia }\end{array}$ & $\begin{array}{c}\text { Nilai } \\
\text { Matkul } \\
\text { Jaringan }\end{array}$ \\
\hline 1 & $\begin{array}{l}\text { Rosita Ayu } \\
\text { Lesta }\end{array}$ & 3,41 & 3,5 & 3,5 & 2,5 \\
\hline 2 & $\begin{array}{l}\text { Sidik Agus } \\
\text { Triyono }\end{array}$ & 2,99 & 3,5 & 3 & 2 \\
\hline 3 & Khoerunisa & 3,52 & 3,5 & 3,5 & 3,5 \\
\hline 4 & $\begin{array}{l}\text { Akbar } \\
\text { Yudistura Al } \\
\text { Hakami }\end{array}$ & 3,33 & 3,25 & 2,75 & 2,5 \\
\hline 5 & Oji Ifandi & 3,39 & 3,5 & 3,5 & 3 \\
\hline 6 & $\begin{array}{l}\text { Silvani } \\
\text { Margita } \\
\text { Saputri }\end{array}$ & 3,52 & 3,5 & 3,5 & 2,5 \\
\hline 7 & $\begin{array}{l}\text { Muhammad } \\
\text { Azmi Tri } \\
\text { Andika }\end{array}$ & 3,01 & 3 & 3,5 & 2 \\
\hline 8 & $\begin{array}{l}\text { Janatin } \\
\text { Karomatul } \\
\text { Afriyani }\end{array}$ & 3,78 & 4 & 4 & 4 \\
\hline 9 & $\begin{array}{l}\text { Uji Irfan } \\
\text { Fauzi }\end{array}$ & 3,41 & 3,5 & 3,5 & 2,5 \\
\hline 10 & $\begin{array}{l}\text { Danang } \\
\text { Prastyo }\end{array}$ & 3,42 & 3,5 & 3,5 & 3,5 \\
\hline 11 & $\begin{array}{l}\text { Ifandi Putra } \\
\mathrm{Aji}\end{array}$ & 3,63 & 4 & 4 & 3 \\
\hline 12 & $\begin{array}{l}\text { Isna } \\
\text { Fatkhiyatul } \\
\text { Azka }\end{array}$ & 3,31 & 3,5 & 3,5 & 3 \\
\hline 13 & $\begin{array}{l}\text { Haekal Alfi } \\
\text { Edy }\end{array}$ & 3,15 & 3,5 & 3 & 3 \\
\hline 14 & $\begin{array}{l}\text { Febrilania } \\
\text { Nur Islami }\end{array}$ & 3,47 & 3,5 & 4 & 3,5 \\
\hline 15 & $\begin{array}{l}\text { Amira Nabila } \\
\text { Zakiyyah }\end{array}$ & 3,56 & 3,5 & 3,5 & 3,5 \\
\hline 16 & $\begin{array}{l}\text { Tiyo Nur } \\
\text { Pratomo }\end{array}$ & 3,63 & 4 & 4 & 3,5 \\
\hline 17 & Hidayatul & 3,15 & 3,5 & 3,5 & 2,5 \\
\hline
\end{tabular}




\begin{tabular}{c|l|c|c|c|c}
\hline & Mustafid & & & & \\
\hline \multirow{2}{*}{18} & $\begin{array}{l}\text { Nofan } \\
\text { Prayowan } \\
\text { Riftiadi }\end{array}$ & 3,12 & 3,5 & 3 & 2 \\
\hline 19 & $\begin{array}{l}\text { Amilatun } \\
\text { Lazmi }\end{array}$ & 3,25 & 3,5 & 4 & 2 \\
\hline 20 & Dinda & 3,51 & 3,25 & 4 & 5,5 \\
\hline
\end{tabular}

\section{HASIL}

pada tahap ini penulis mengaplikasikan data Data Calon Asisten Laboratorium memakai algoritma K-Means Clustering di perangkat lunak Rapid Miner. kelompok pertama terlihat di garis yang ditandai menggunakan warna biru dan pusat cendroid pertama terletak di titik $3.392 ; 3.500 ; 3.147 ; 3.250$. kelompok kedua ditandai menggunakan garis warna hijau dengan pusat clusternya di titik 3.604; 3.750; 4; tiga.500. kelompok ketiga ditandai menggunakan garis warna merah dengan pusat clusternya di titik 3.243; tiga.417; 3.361; dua.278. hasil Cluster bisa dilihat pada gambar dibawah ini:

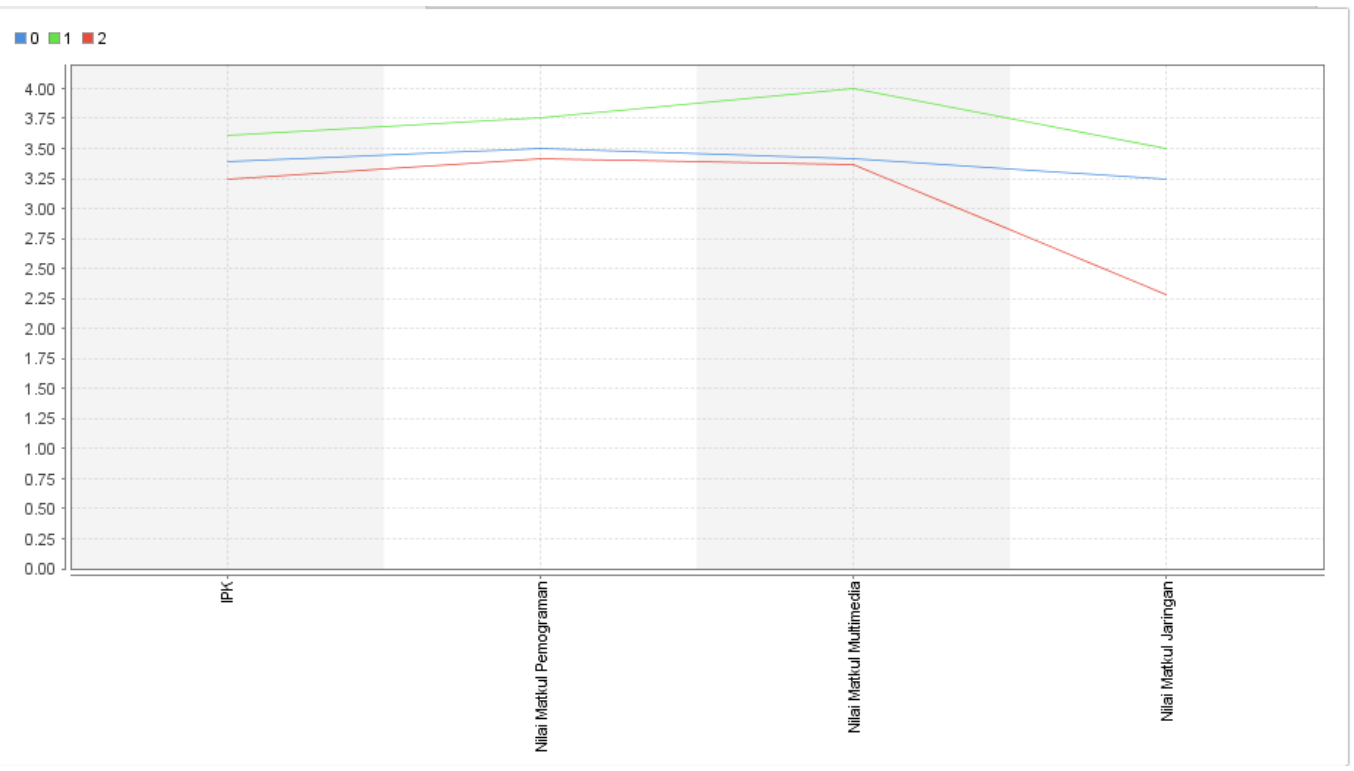

Gambar 2. Diagram Pemetaan Clustering

Data pada algoritma klasifikasi $K$-Menas dikelompokan menjadi 3 kelompok, berikut adalah langkah dalam perhitungan cluster:

- Tentukan pusat cluster secara random, missal ditentukan $C_{1}=(3,01 ; 3 ; 3,5 ; 2) ; C_{2}=$ $(3,15 ; 3,5 ; 3 ; 3)$; dan $\mathrm{C}_{3}=(3,33 ; 3,25 ; 2,75 ; 2,5)$;

- Hitung jarak setiap data terhadap setiap pusat clustering. model, menghitung jarak data calon asisten laboratorium pertama menggunakan pusat cluster pertama, yaitu:

$$
d_{11}=\sqrt{(3,41-3,01)^{2}+(3,5-3)^{2}+(3,5-3,5)^{2}+(2,5-2)^{2}}=0,81
$$

Jarak data calon asisten laboratorium pertama dengan pusat cluster kedua:

$$
d_{12}=\sqrt{(3,41-3,15)^{2}+(3,5-3,5)^{2}+(3,5-3)^{2}+(2,5-3)^{2}}=0,75
$$

Jarak data calon asisten laboratorium pertama dengan pusat cluster ketiga:

$$
d_{13}=\sqrt{(3,41-3,33)^{2}+(3,5-3,25)^{2}+(3,5-2,75)^{2}+(2,5-2)^{2}}=0,79
$$

Hasil perhitungan selengkapnya pada table 2 terkait hasil perhitungan pada iterasi pertama. 
Tabel 2. Hasil Iterasi pertama

\begin{tabular}{c|c|c|c|c|r|r}
\hline $\begin{array}{c}\text { Cal. } \\
\text { AsLab. }\end{array}$ & $\mathrm{c} 1$ & $\mathrm{c} 2$ & $\mathrm{c} 3$ & $\mathrm{c} 1$ & $\mathrm{c} 2$ & $\mathrm{c} 3$ \\
\hline 1 & 0,81 & $\mathbf{0 , 7 5}$ & 0,79 & & $*$ & \\
\hline 2 & 0,71 & 1,01 & $\mathbf{0 , 7 0}$ & & & $*$ \\
\hline 3 & 1,66 & 0,80 & $\mathbf{1 , 2 9}$ & & & $*$ \\
\hline 4 & 0,99 & 0,64 & $\mathbf{0 , 0 0}$ & & & $*$ \\
\hline 5 & 1,18 & $\mathbf{0 , 5 5}$ & 0,94 & & $*$ & \\
\hline 6 & 0,87 & $\mathbf{0 , 8 0}$ & 0,81 & & $*$ & \\
\hline 7 & $\mathbf{0 , 0 0}$ & 1,23 & 0,99 & $*$ & & \\
\hline 8 & 2,42 & $\mathbf{1 , 6 3}$ & 2,14 & & $*$ & \\
\hline 9 & 0,81 & $\mathbf{0 , 7 5}$ & 0,79 & & $*$ & \\
\hline 10 & 1,63 & $\mathbf{0 , 7 6}$ & 1,28 & & $*$ & \\
\hline 11 & 1,62 & $\mathbf{1 , 2 2}$ & 1,57 & & $*$ & \\
\hline 12 & 1,16 & $\mathbf{0 , 5 2}$ & 0,94 & & $*$ & \\
\hline 13 & 1,23 & $\mathbf{0 , 0 0}$ & 0,64 & & $*$ & \\
\hline 14 & 1,72 & $\mathbf{1 , 1 6}$ & 1,63 & & $*$ & \\
\hline 15 & 1,67 & 0,82 & $\mathbf{1 , 3 0}$ & & & $*$ \\
\hline 16 & 1,97 & $\mathbf{1 , 3 2}$ & 1,79 & & $*$ & \\
\hline 17 & 0,72 & $\mathbf{0 , 7 1}$ & 0,81 & & $*$ & \\
\hline 18 & 0,72 & 1,00 & $\mathbf{0 , 6 5}$ & & & $*$ \\
\hline 19 & $\mathbf{0 , 7 5}$ & 1,42 & 1,37 & $*$ & & \\
\hline 20 & 3,58 & $\mathbf{2 , 7 3}$ & 3,25 & & $*$ & \\
\hline
\end{tabular}

- Hitung pusat cluster baru, dengan cluster pertama, ada 2 data, yaitu data ke-7 dan 19, sehingga:

$$
\begin{array}{ll}
C_{11}=\frac{(3,01+3,25)}{2}=3,13 & C_{13}=\frac{(3,5+4)}{2}=3,75 \\
C_{12}=\frac{(3+3,5)}{2}=3,25 & C_{14}=\frac{(2+2)}{2}=2
\end{array}
$$

Untuk cluster kedua, ada 13 data, yaitu data ke-1, 5, 6, 8, 9, 10, 11, 12, 13, 14, 16, 17, dan 20, sehingga:

$$
\begin{aligned}
& (3,41+3,39+3,52+3,78+3,41+3,42+3,63+3,31+3,15 \\
& C_{21}=\frac{+3,47+3,63+3,15+3,41)}{13}=3,44 \\
& C_{22}=\frac{(3,5+3,5+3,5+4+3,5+3,5+4+3,5+3,5+3,5+4+3,5+3,25)}{13} \\
& =3,60 \\
& C_{23}=\frac{(3,5+3,5+3,5+4+3,5+3,5+4+3,5+3+4+4+3,5+4)}{13}=3,65 \\
& C_{24}=\frac{(2,5+3+2,5+4+2,5+3,5+3+3+3+3,5+3,5+2,5+3,5)}{13}=3,08
\end{aligned}
$$

Untuk cluster ketiga, ada 5 data, yaitu data ke-2, 3, 4, 15, dan 18, sehingga: 


$$
\begin{array}{cc}
C_{31}=\frac{(2,99+3,52+3,33+3,5+3,12)}{5} & C_{33}=\frac{(3+3,5+2,75+3,5+3)}{5} \\
=3,30 & =3,15 \\
C_{32}=\frac{(3,55+3,55+3,25+3,5+3,5)}{5} & C_{34}=\frac{(3+3,5+2,5+3,5+2)}{5}=2,70 \\
=3,45 &
\end{array}
$$

1. Ulangi perhitungan langkah 2 sehingga posisi data tidak mengalami perubahan dan cluster tidak berpindah.

2. Data dari hasil perhitungan manual, kemudian diuji menggunakan aplikasi Rapid Miner dengan memasukan data tersebut. Tampilan pengujian Cluster Model dengan model $\mathrm{K}$ Means Clustering pada gambar 1 adalah hasil dari perhitugan dengan nilai k berjumlah 3 dan tiap-tiap anggota dari ke 3 cluster ditampilkan pada gambar 2 .

\section{Cluster Model}

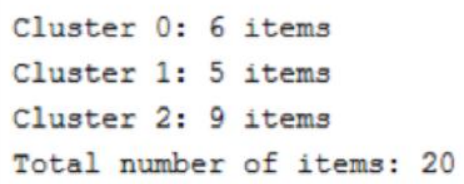

Gambar 3. Cluster Model

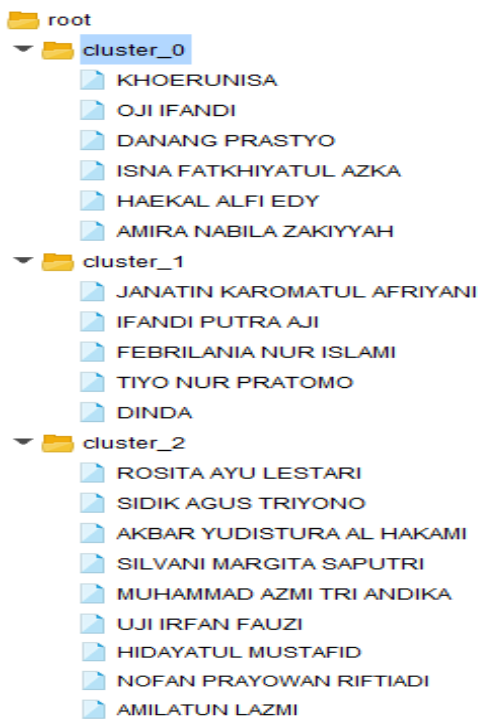

Gambar 4. Tampilan Setiap Anggota Clustering

Posisi cluster tidak mengalami perubahan dan hasil akhir ke 3 cluster, dengan melihat hasil centroid akhir (gambar 5) 


\begin{tabular}{|l|l|l|l|}
\hline Attribute & cluster_0 & cluster_1 & cluster_2 \\
\hline IPK & 3.392 & 3.604 & 3.243 \\
\hline Nilai Matkul Pemograman & 3.500 & 3.750 & 3.417 \\
\hline Nilai Matkul Multimedia & 3.417 & 4 & 3.361 \\
\hline Nilai Matkul Jaringan & 3.250 & 3.500 & 2.278 \\
\hline
\end{tabular}

Gambar 5. Hasil Centroid Akhir

\section{KESIMPULAN}

Pada penelitian yang dilakukan menggunakan algoritma K-Means dapat digunakan dalam pengelompokan calon asisten laboratorium Teknik Informatika Universtias Peradaban. Hasil dari data yang dilatih, disimpulkan 3 kelompok berdasarkan IPK, nilai matakuliah Pemograman, nilai matakuliah Multimedia, dan nilai matakuliah Jaringan, yaitu:

1. Ditemukan pusat cluster dengan cluster 1 adalah $(3,392 ; 3,5 ; 3,417 ; 3,25)$, cluster 2 adalah $(3,604 ; 3,75 ; 4 ; 3,5)$ dan cluster 3 adalah $(3,243 ; 3,417 ; 3,361 ; 2,278)$.

2. Hasil Clustering diatas diperoleh kesimpulan adalah bahwa jika cluster 1 adalah termasuk prestasi Menengah, cluster 2 adalah termasuk prestasi tinggi dan cluster 3 termasuk prestasi rendah.

3. Nilai centroid awal akan mempengaruhi yang digunakan serta jumlah data yang digunakan, perbedaan pengambilan data pusat cendroid awal yang digunakan juga akan mempengaruhi hasil cendroid akhirnya.

\section{Daftar Pustaka}

[1] M. L. Sibuea and A. Safta, "Pemetaan Siswa Berprestasi Menggunakan Metode KMeans Clustring," JURTEKSI, 2017, doi: 10.33330/jurteksi.v4i1.28.

[2] T. N. Hermawan, M. Ugiarto, and N. Puspitasari, "Sistem Evaluasi Kinerja Asisten Laboratorium Menggunakan Metode K-Means," Pros. Semin. Nas. Ilmu Komput. dan Teknol. Inf., vol. 3, no. 2, pp. 3-6, 2017.

[3] A. Wanto and E. Kurniawan, "SELEKSI PENERIMAAN ASISTEN LABORATORIUM MENGGUNAKAN ALGORITMA AHP PADA AMIK-STIKOM TUNAS BANGSA PEMATANGSIANTAR," JIKO (Jurnal Inform. dan Komputer), 2018, doi: 10.26798/jiko.2018.v3i1.106.

[4] F. Nasari, S. Informasi, P. Keputusan, and D. Selection, "Penerapan algoritma c4.5 dalam pemilihan bidang peminatan program studi sistem informasi di stmik potensi utama medan," SNIf, vol. 1, pp. 30-34, 2014.

[5] Ediyanto, M. N. Mara, and N. Satyahadewi, "Pengklasifikasian Karakteristik Dengan Metod K-Means Cluster Analysis,” Bul. Ilm., vol. 02, no. 2, pp. 133-136, 2013.

[6] J. O. Ong, "Implementasi Algotritma K-means clustering untuk menentukan strategi marketing president university," J. Ilm. Tek. Ind., vol. vol.12, no, no. juni, pp. 10-20, 2013.

[7] T. Gomasathit, "Available Online at www.jgrcs.info CLOUD COVERAGE IDENTIFICATION USING SATELLITE DATA AND K-MEAN CLUSTERING ALGORITHM,” J. Glob. Res. Comput. Sci., vol. 4, no. 7, pp. 33-37, 2013. 
[8] B. Mirkin, "Clustering: A Data Recovery Approach.” London UK: Chapman \& Hall/CRC, 2012.

[9] M. Imron, "Penerapan data mining algoritma naive bayes dan part untuk mengetahui minat baca mahasiswa di perpustakaan STMIK AMIKOM Purwokerto," Telematika, vol. 10, no. 2, pp. 121-135, 2017.

[10] R. A. Asroni, "Penerapan Metode K-Means Untuk Clustering Mahasiswa Berdasarkan Nilai Akademik Dengan Weka Interface Studi Kasus Pada Jurusan Teknik Informatika UMM Magelang," Ilm. Semesta Tek., vol. 18, no. 1, pp. 76-82, 2015, doi:

10.1038/hdy.2009.180.

[11] J. . W. Garcia, H. M.; ULLMAN and Jennifer, Database systems: The complete book. 2002.

[12] S. Andayani, "Formation of clusters in Knowledge Discovery in Databases by Algorithm K-Means," SEMNAS Mat. dan Pendidik. Mat. 2007, 2007.

[13] R. M. Cormack, B. S. Duran, and P. L. Odell, "Cluster Analysis: A Survey.," J. R. Stat. Soc. Ser. A, 1976, doi: 10.2307/2344396.

[14] Y. Agusta, "K-Means-Penerapan, Permasalahan dan Metode Terkait," J. Sist. dan Inform., 2007. 